\title{
KELEKATAN PADA PENGASUHAN NENEK
}

\author{
Triska Novira dan Zulian Fikry \\ Jurusan Psikologi, Fakultas Ilmu Pendidikan, Universitas Negeri Padang, Bukittinggi \\ Email: triskanovira.psi@gmail.com
}

\begin{abstract}
Abstrak
Kelekatan antara anak dengan orang tua merupakan salah satu topik yang banyak dibahas dalam psikologi perkembangan. Namun fenomena di lapangan menunjukkan tidak semua anak diasuh oleh orang tua kandung mereka. Maka penelitian ini dilakukan untuk melihat seperti apa kelekatan yang terbentuk antara anak dengan pengasuh selain orang tua, yang difokuskan pada nenek. Penelitian ini dilakukan menggunakan metode kualitatif fenomenologi. Subjek penelitian ini berjumlah empat orang yang diasuh neneknya sejak kecil. Pengambilan data dilakukan dengan kuisioner dan wawancara. Analisis data yang dilakukan menggunakan teknik tematik menunjukkan bahwa pengasuhan oleh nenek dapat membentuk kelekatan aman.
\end{abstract}

Kata kunci: kelekatan, pengasuhan, nenek, psikologi perkembangan

\section{ATTACHMENT IN GRANDMOTHER'S PARENTING}

\begin{abstract}
Attachment between children and parents is one of the topics discussed in developmental psychology. However, phenomena in the field show that not all children are cared for by their biological parents. So this research was conducted to see what kind of attachment is formed between the child and the caregiver beside the parents, which is focused on the grandmother. This research was conducted using a phenomenological qualitative method. The subjects of this study were four people who had been cared for by their grandmother since childhood. Data were collected by questionnaires and interviews. Data analysis carried out using thematic techniques shows that grandmother's care can establish secure attachment.
\end{abstract}

Keywords: attachment, parenting, grandmother, developmental psychology

\section{Pendahuluan}

Psikologi perkembangan menjelaskan bahwa anak biasanya berada dalam pengasuhan keluarga intinya. Anak yang diasuh oleh orang tua, umumnya akan menunjukkan kelekatan kepada ibu sebagai figur utama, lalu kepada ayah, dan kemudian diikuti oleh keluarga lain (Cenceng, 2015). Namun pada kenyataannya tidak semua anak diasuh oleh keluarga inti. Ada beberapa hal yang menyebabkan anak harus diasuh oleh nenek, kakek, atau keluarga lainnya. Hal ini dapat terjadi karena beberapa alasan seperti orang tua meninggal dunia, orang tua bekerja, dan orang tua yang bercerai.

Data yang disampaikan oleh Komisi Perlindungan Anak Indonesia (2018), terdapat tujuh puluh lima persen anak di Indonesia yang diasuh oleh selain orang tua. Sekitar empat belas persen anak di Indonesia diasuh oleh kakek neneknya. Angka ini merupakan jumlah yang cukup besar untuk menjadi perhatian, khususnya dalam bidang penelitian psikologi perkembangan. 
Ada berbagai penelitian yang menjelaskan tentang pengaruh yang diperoleh dari pengasuhan selain orang tua. Pengasuhan selain orang tua ditemukan dapat berpengaruh negatif pada kesehatan fisik, mental, serta perilaku anak (Desrosiers et al., 2013). Pengasuhan oleh kakek nenek menjadikan anak menunjukkan sikap yang negatif dibandingkan dengan pengasuhan oleh orang tua (Edwards, 2018). Dampak negatif dari pengasuhan kakek nenek juga ditemukan berpengaruh pada proses belajar anak di sekolah dan perilaku anak dengan teman serta gurunya (Statham, 2011). Anak yang tinggal dengan selain orang tua menunjukkan respon emosional yang cenderung negatif seperti merasa kurang percaya diri, takut, malu, bahkan sakit hati dan merindukan orang tuanya namun tidak mampu untuk mengungkapkannya (Beazley et al., 2018).

Penelitian mengenai kelekatan pada pengasuhan selain orang tua masih sangat kurang memadai di Indonesia, maka penelitian ini dilakukan untuk mendapatkan informasi yang lebih jauh mengenai hubungan anak dengan pengasuh selain orang tua. Fokus penelitian ini yaitu pada pengasuhan nenek.

Pentingnya penelitian mengenai kelekatan pada pengasuhan nenek ini dilakukan untuk memperkaya pengetahuan dalam bidang psikologi perkembangan serta menambah informasi mengenai kelekatan yang tidak selalu dengan orang tua kandung saja. Penelitian ini juga diharapkan dapat memberi manfaat bagi orang tua maupun pengasuh lain jika harus berpisah dengan anak, agar anak tetap memiliki perkembangan yang baik.

Penelitian ini merumuskan pertanyaan penelitian yaitu: apakah anak yang diasuh nenek memiliki kelekatan yang aman?

\section{Kelekatan (Attachment)}

Menurut Ainsworth dan Bowlby (1991), kelekatan merupakan ikatan yang terbentuk antara anak dengan ibu (atau pengasuh lain) sehingga membuat anak merasa aman dan nyaman jika berada di dekat sang ibu. Anak akan selalu mengandalkan kehadiran ibu sebagai tumpuan mereka, maka ketidakhadiran figur ibu akan membuat anak cemas bahkan berpengaruh buruk pada perkembangan anak. Kelekatan menurut Papalia et al. (2009) adalah hubungan emosional antara bayi dengan ibu atau pengasuh lainnya yang bersifat timbal balik serta bertahan dalam waktu yang lama. Pembahasan kelekatan dalam bidang psikologi perkembangan yang awalnya berfokus pada bayi, kini telah semakin berkembang hingga usia prasekolah, remaja, dan dewasa (Ainsworth \& Bowlby, 1991).

Ainsworth (dalam Ainsworth \& Bowlby, 1991) mengemukakan tiga jenis kelekatan yaitu kelekatan aman (securely attached), kelekatan tidak aman (insecurely attached), dan tidak lekat (nonattached). Kelekatan aman dicirikan dengan keinginan bayi untuk selalu berada di dekat ibunya sehingga bayi akan menangis ketika ditinggal oleh sang ibu. Berbeda dengan bayi yang memiliki kelekatan tidak aman dengan ibunya, bayi sering menangis meskipun sang ibu berada di sisinya. Kemudian jenis tidak lekat biasanya disebabkan karena sang ibu kurang peduli dengan bayinya, namun jenis ini dianggap oleh Ainsworth masih dapat berkembang menjadi hubungan yang lebih lekat.

Terdapat tiga aspek kelekatan yang dikemukakan Bowlby (dalam Armsden \& Greenberg (1987) yaitu kepercayaan, komunikasi, dan keterasingan. Kepercayaan, yaitu anak yakin bahwa figur lekatnya akan selalu ada untuknya, memberi bantuan ketika dibutuhkan, peduli serta menyayanginya, serta selalu memahaminya. Komunikasi yang terjalin antara anak dengan figur lekatnya dapat terjadi sehari-hari, saling bercerita, atau bahkan ketika anak semakin dewasa dapat 
melakukan komunikasi tidak langsung seperti melalui telepon atau panggilan video. Keterasingan, biasa ditunjukkan dengan perasaan marah dan merasa tidak diperhatikan oleh orang tua.

Kelekatan yang aman dapat dilihat dari baiknya hubungan antara anak dengan pengasuhnya dalam aspek komunikasi dan kepercayaan. Tingginya aspek pengasingan yang dialami dalam pengasuhan justru akan menunjukkan kelekatan yang tidak aman dalam hubungan anak dengan pengasuhnya. Maka untuk menilai kelekatan aman anak dengan pengasuhnya, akan tampak skor yang tinggi pada kualitas komunikasi dan kepercayaan, serta skor rendah pada perasaan terasing. (Armsden \& Greenberg, 1987)

\section{Metode Penelitian}

Penelitian ini merupakan penelitian kualitatif fenomenologi. Sugiyono,( 2012) menjelaskan bahwa penelitian kualitatif merupakan penelitian yang bertujuan untuk mendapatkan gambaran mendalam pada topik yang diteliti. Pada penelitian kualitatif, generalisasi tidak bisa dilakukan. Namun tetap dapat dilakukan transferability, yaitu melakukan penelitian yang serupa di tempat lain dengan masalah yang sama. Fenomenologi dipilih sebagai bagian dari penelitian ini. Metode fenomenologi merupakan metode yang digunakan untuk mencari tahu seperti apa cara individu memaknai pengalaman hidupnya mengenai hal yang sedang diteliti (Creswell \& Poth, 2018).

Penelitian kualitatif menyebut populasi sebagai situasi sosial (Sugiyono, 2013). Situasi sosial yang diteliti saat ini adalah ketika individu tinggal dengan nenek sejak ia masih kecil. Maka sampel yang digunakan adalah purposive samping yaitu memilih subjek dengan memperhatikan kriteria tertentu. Peneliti memilih subjek berusia dewasa awal yang tinggal dengan nenek sejak kecil. Subjek pada penelitian ini berjumlah empat orang dewasa awal yang berasal dari beberapa wilayah di Indonesia yaitu Aceh, Karanganyar, Medan, dan Purworejo. Rentang usia dewasa awal menurut Papalia,Olds, dan Feldman (2009) yaitu pada usia 20 hingga 40 tahun. Sedangkan usia akhir masa kanak-kanak berada pada usia 11 tahun.

Instrumen penelitian utama dalam penelitian kualitatif adalah peneliti. Pengumpulan data dalam penelitian ini menggunakan kuisioner, wawancara, dan dokumentasi. Proses pengambilan data awal pada penelitian ini menggunakan kuisioner singkat yang dibagikan melalui google form mengenai data awal dan kesediaan subjek untuk menjadi narasumber dalam penelitian ini. Setelah menemukan subjek yang sesuai, selanjutnya dilakukan wawancara. Wawancara merupakan proses tanya jawab antara dua orang untuk memperoleh informasi mengenai topik tertentu. Wawancara dilakukan menggunakan metode wawancara semi terstruktur dimana peneliti telah membuat pedoman wawancara namun dalam pelaksanaannya dapat fleksibel sesuai jawaban subjek (Esterberg, 2002). Wawancara dilakukan secara langsung dan melalui media. Wawancara awal dilakukan melalui pesan Whatsapp dan pesan facebook pada masing-masing subjek. Setelah itu peneliti menyiapkan pedoman wawancara dan membuat janji dengan subjek untuk melakukan wawancara secara online dan offline. Selanjutnya dilakukan wawancara lebih mendalam, satu orang subjek diwawancarai secara langsung karena berada di kota yang sama dengan peneliti. Tiga subjek lainnya diwawancarai melalui media telepon dan pesan whatsapp mengingat jauhnya jarak antara subjek dengan peneliti, keterbatasan waktu yang dimiliki, serta kesibukan subjek. Dokumentasi dalam penelitian ini dilakukan sejak penyebaran kuisioner hingga proses wawancara yang berupa foto dan rekaman suara. 
Analisis data dilakukan dengan teknik analisis tematik, yaitu analisis yang dilakukan dalam penelitian kualitatif untuk mencari suatu pola maupun tema tertentu dari data penelitian yang telah diperoleh (Braun \& Clarke, 2006). Tahapan dalam melakukan analisis tematik ini menurut Maguire dan Delahunt (2017) yaitu 1) kumpulkan dan pahami data yang telah terkumpul; 2) melakukan koding data; 3) tentukan tema pada data yang telah dikoding; 4) melakukan peninjauan ulang pada tema yang telah ditemukan; 5) memberi judul atau pada setiap tema; 6) lalu yang terakhir menuliskan semua analisis yang telah dilakukan pada artikel atau laporan penelitian.

Pengujian validitas dalam penelitian ini dilakukan dengan metode peer debriefing. Janesick (2007) menjelaskan bahwa peer debriefing merupakan metode yang dilakukan dengan meminta rekan peneliti untuk meninjau kembali data penelitian, interpretasi data, hingga hasil akhir penelitian. Hal ini dilakukan untuk lebih mengkritisi data serta memperoleh kesamaan perspektif. Peneliti meminta dua orang peneliti kualitatif untuk menjadi peer debriefer.

\section{Analisis dan Interpretasi Data}

\section{Subjek}

Penelitian ini diawali dengan penyebaran kuisioner melalui google form dan diperoleh 17 responden. Namun dari 17 responden tersebut yang sesuai dengan kriteria hanya 2 orang. Jumlah subjek yang berpartisipasi dalam penelitian ini hingga akhir berjumlah 4 orang, yaitu 2 orang subjek yang mengisi google form, 1 orang subjek yang dikenalkan oleh rekan peneliti, dan 1 orang subjek yang sudah dikenal oleh peneliti sebelumnya.

Tabel 1. Identitas Subjek

\begin{tabular}{ccccc}
\hline No. & Inisial & Usia & Domisili & Tinggal dengan nenek sejak usia \\
\hline 1. & $\mathrm{~B}$ & 22 tahun & Karanganyar & 7 tahun \\
2. & $\mathrm{D}$ & 21 tahun & Aceh & 5 tahun \\
3. & $\mathrm{~A}$ & 22 tahun & Medan & 9 bulan \\
4. & $\mathrm{~N}$ & 21 tahun & Purworejo & 22 hari \\
\hline
\end{tabular}

\section{Kelekatan dengan Nenek}

Kelekatan anak yang diasuh oleh nenek sejak kecil, dianalisis berdasarkan jawaban subjek atas pertanyaan dari peneliti yang mencakup tiga aspek kelekatan yaitu komunikasi, kepercayaan, dan keterasingan: 
Tabel 2. Aspek Kelekatan

\begin{tabular}{|c|c|c|c|}
\hline Subje & Aspek Komunikasi & Aspek Kepercayaan & Aspek Keterasingan \\
\hline B & $\begin{array}{l}\text { Ada komunikasi yang terjalin } \\
\text { antara subjek dengan nenek } \\
\text { dan kakek. Namun subjek } \\
\text { lebih banyak bercerita } \\
\text { kepada ibunya karena nenek } \\
\text { yang sibuk. }\end{array}$ & $\begin{array}{l}\text { Subjek menganggap nenek } \\
\text { dan kakek sebagai sosok orang } \\
\text { tua dan mendapatkan kasih } \\
\text { sayang dari keduanya. Selama } \\
\text { tinggal dengan kakek dan } \\
\text { nenek, subjek merasa bahwa } \\
\text { ibu tetap menjadi tempat } \\
\text { berbagi cerita dan selalu ada } \\
\text { disaat subyek membutuhkan. }\end{array}$ & $\begin{array}{l}\text { Subjek merasa iri } \\
\text { dengan anak yang bisa } \\
\text { tinggal dengan orang } \\
\text { tua. }\end{array}$ \\
\hline $\mathrm{D}$ & $\begin{array}{l}\text { Subjek biasanya berbagi } \\
\text { cerita dan bertukar } \\
\text { pendapat dengan nenek dan } \\
\text { masih sering bertemu } \\
\text { dengan nenek meskipun } \\
\text { sekarang sudah tidak tinggal } \\
\text { serumah. Subjek memilih } \\
\text { tidak menceritakan semua } \\
\text { hal karena terkadang nenek } \\
\text { tidak paham akan hal yang } \\
\text { dibicarakan. Subjek juga } \\
\text { memilih untuk tidak } \\
\text { menceritakan hal yang akan } \\
\text { membuat nenek sedih. }\end{array}$ & $\begin{array}{l}\text { Subjek mendapatkan sosok } \\
\text { orang tua dari nenek dan } \\
\text { kakek. Nenek merupakan } \\
\text { sosok yang selalu ada } \\
\text { untuknya ketika ia butuhkan. } \\
\text { Subjek dan nenek } \\
\text { menunjukkan kepeduliannya } \\
\text { satu sama lain. }\end{array}$ & $\begin{array}{l}\text { Subjek merasakan } \\
\text { kesedihan dan juga iri } \\
\text { dengan anak yang } \\
\text { tinggal bersama kedua } \\
\text { orang tua. }\end{array}$ \\
\hline$A$ & $\begin{array}{l}\text { Komunikasi subjek dengan } \\
\text { neneknya baik, sering } \\
\text { ngobrol, dan saling curhat. } \\
\text { Namun subjek memilih } \\
\text { untuk tidak menceritakan hal } \\
\text { yang serius karena respon } \\
\text { neneknya yang mudah } \\
\text { terbawa emosi. Ketika ada } \\
\text { hal yang perlu dibicarakan, } \\
\text { subjek dan nenek akan } \\
\text { membicarakannya bersama. }\end{array}$ & $\begin{array}{lr}\text { Subjek merasa bahwa nenek } \\
\text { dan kakeknya seperti orang } \\
\text { tuanya sendiri, bahkan } \\
\text { memanggil neneknya dengan } \\
\text { sebutan mamak. } & \text { Nenek } \\
\text { merupakan orang yang } \\
\text { senantiasa ada ketika } \\
\text { dibutuhkan dan yang paling } \\
\text { peduli dengannya. Namun } \\
\text { nenek subjek tampak tidak } \\
\text { percaya sepenuhnya kepada } \\
\text { subjek dengan selalu } \\
\text { menerapkan pola asuh yang } \\
\text { ketat. }\end{array}$ & $\begin{array}{l}\text { Subjek merasa tidak } \\
\text { memiliki sosok yang } \\
\text { peduli padanya, namun } \\
\text { setelah berpikir } \\
\text { beberapa saat subjek } \\
\text { memilih nenek yang } \\
\text { paling peduli padanya. }\end{array}$ \\
\hline $\mathrm{N}$ & $\begin{array}{l}\text { Komunikasi subjek dengan } \\
\text { nenek baik, mereka sering } \\
\text { bercerita. Namun saat itu } \\
\text { komunikasi tidak sesering }\end{array}$ & $\begin{array}{l}\text { Subjek menganggap nenek } \\
\text { dan pamannya sebagai orang } \\
\text { tua walaupun ia tetap merasa } \\
\text { ada perbedaan dengan orang }\end{array}$ & 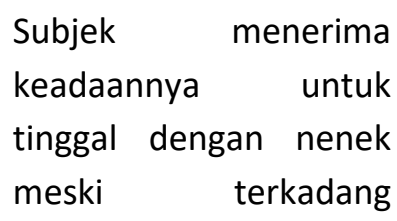 \\
\hline \multicolumn{4}{|c|}{\begin{tabular}{l|l}
65 & E-ISSN 2656-4173 \\
& P-ISSN $1907-8455$
\end{tabular}} \\
\hline
\end{tabular}




$\begin{array}{lllllr}\text { dulu karena nenek } & \text { yang } & \text { tua yang sebenarnya. Sosok merasa iri dengan } \\ \text { sudah mulai pikun serta } & \text { yang paling sering ada ketika } & \text { keluarga lain. Nenek } \\ \text { kurang mengerti ketika } & \text { subjek butuhkan ialah sang dan paman yang } \\ \text { subjek bercerita. } & & \text { nenek. } & \text { dianggap subjek seperti } \\ & & & \text { orang tuanya sendiri } \\ & & \text { tetap dirasa ada } \\ & & \text { perbedaan dengan } \\ & & \text { orang tua kandung. }\end{array}$

\section{Hubungan subyek dengan Orang Tua}

Gambaran mengenai kedekatan antara subyek dengan orang tua dijelaskan pada tabel 3 di bawah ini:

Tabel 3. Hubungan subyek dengan orang tua

\begin{tabular}{|c|c|}
\hline Subjek & Hubungan dengan Orang Tua \\
\hline B & $\begin{array}{l}\text { Subjek jarang berkomunikasi maupun bertemu dengan ibu meski ibunya masih hidup } \\
\text { karena tidak diizinkan oleh ayah tirinya. Meskipun subjek jauh dengan ibu, subjek tetap } \\
\text { merasa nyaman dengannya. }\end{array}$ \\
\hline D & $\begin{array}{l}\text { Ketika ibu subjek masih hidup dan bekerja di luar negeri, subjek berkomuikasi lewat } \\
\text { telepon hampir setiap minggu. }\end{array}$ \\
\hline A & $\begin{array}{l}\text { Subjek masih bertemu dengan ayah maupun ibunya namun tidak pernah menelepon, } \\
\text { dan Subjek merasa tidak dekat dengan ayah. }\end{array}$ \\
\hline $\mathrm{N}$ & $\begin{array}{l}\text { Sejak tinggal dengan nenek dan pamannya, setiap bulan orang tua subjek datang } \\
\text { berkunjung dan setiap minggunya menelepon. Namun setelah SD, frekuensi subjek } \\
\text { bertemu dan menelepon orang tuanya semakin berkurang. } \\
\text { Sang ibu ikut tinggal dengannya dan nenek pada saat ia di bangku SMA hingga sekarang. } \\
\text { Komunikasi subjek dengan ayah masih tetap berjalan hingga sekarang melalui telepon } \\
\text { dan sesekali bertemu. }\end{array}$ \\
\hline
\end{tabular}

\section{Pengaruh Pengasuhan Nenek}

Pola asuh yang diterapkan nenek berpengaruh terhadap perkembangan subyek seperti yang dijelaskan pada tabel 4 di bawah ini: 
Tabel 4. Pengaruh pengasuhan nenek

\begin{tabular}{|c|c|}
\hline Subjek & Pengaruh Pengasuhan Nenek \\
\hline B & $\begin{array}{l}\text { Subjek memiliki sifat kerja keras dan mandiri karena sejak kecil dididik untuk tidak manja. } \\
\text { Subjek tetap melihat banyak hal dengan positif meskipun itu tidak sesuai keinginannya. } \\
\text { Subjek senantiasa mengikhlaskan semua yang terjadi dan bahagia atas hidupnya. } \\
\text { Pengasuhan nenek dan kakek kepada subjek ingin diterapkan pula kepada anaknya kelak. }\end{array}$ \\
\hline D & $\begin{array}{l}\text { Subjek merasa sang nenek selalu mendidiknya dengan baik agar ia menjadi orang yang } \\
\text { baik. Subjek memiliki keinginan untuk membanggakan neneknya. Jika mempunyai anak } \\
\text { nanti, subjek ingin anaknya lebih baik darinya. }\end{array}$ \\
\hline A & $\begin{array}{l}\text { Subjek ikhlas menjalani setiap hal yang terjadi dalam hidupnya. Nenek subjek yang mudah } \\
\text { terbawa emosi justru memberi pelajaran bagi subjek agar tidak memilki karakter yang } \\
\text { serupa. Subjek belajar dari orang sekitarnya untuk selalu sabar, mau mengerti keadaan } \\
\text { orang lain, dan tidak mudah terbawa emosi. Pengasuhan nenek yang sangat ketat } \\
\text { membuat subjek tidak ingin anaknya kelak diasuh dengan cara yang sama. Subjek ingin } \\
\text { mengajari anaknya kelak agar memiliki ilmu agama, attitude, adab, dan sopan santun. }\end{array}$ \\
\hline $\mathrm{N}$ & $\begin{array}{l}\text { Nenek subjek mengasuhnya dengan selalu menuruti keinginan subjek sehingga subjek } \\
\text { menjadi anak yang manja. Kesabaran yang dimiliki nenek subjek menjadikannya sebagai } \\
\text { pribadi yang sabar pula. Jika sudah memiliki anak kelak, subjek ingin mendidik anaknya } \\
\text { agar mandiri dan tidak manja namun juga tidak terlalu keras. }\end{array}$ \\
\hline
\end{tabular}

Kelekatan Subjektif

Kelekatan subjektif yang dimiliki subjek dapat dilihat pada tabel 5 dibawah ini:

Tabel 5. Kelekatan subjektif

\begin{tabular}{cl}
\hline Subjek & \multicolumn{1}{c}{ Kelekatan Subjektif } \\
\hline $\mathrm{B}$ & Merasa paling dekat dengan ibu \\
$\mathrm{D}$ & Merasa lebih dekat dengan ibu walaupun ditinggal keluar negeri \\
$\mathrm{A}$ & Merasa paling dekat dengan nenek \\
$\mathrm{N}$ & $\begin{array}{l}\text { Merasa dekat dengan nenek, dan sekarang merasa dekat dengan ibu karena nenek } \\
\text { yang sudah tua }\end{array}$ \\
\hline
\end{tabular}

\section{Pembahasan}

Kelekatan dengan Nenek

Berdasarkan hasil analisis yang telah dipaparkan di atas, keempat subjek memiliki kelekatan aman dengan nenek. Hal ini ditunjukkan dari ketiga aspek kelekatan Bowlby (dalam Armsden \& Greenberg, 1987) yaitu komunikasi, kepercayaan, dan keterasingan.

Subjek B menjalin komunikasi dengan neneknya meskipun ia merasa lebih sering untuk cerita kepada sang ibu dikarenakan nenek yang cukup sibuk. Subjek menganggap nenek sebagai orang tua, namun merasa lebih nyaman dengan ibu. Ibu merupakan sosok yang paling peduli dan selalu ada untuk subjek. Aspek keterasingan tidak ditunjukkan subjek ini, karena ia tidak merasa marah akan kondisinya.

Subjek D merasakan bahwa nenek merupakan sosok yang paling peduli padanya, dan senantiasa berada di samping subjek jika dibutuhkan. Subjek dan nenek menunjukkan rasa 
pengertian satu sama lain. Nenek juga telah dianggap seperti orang tua sendiri bagi subjek. Komunikasi subjek dan nenek terjalin dengan baik, saling bercerita, bertukar pendapat, bahkan masih sering bertemu meski sudah tidak tinggal bersama. Subjek juga memilih untuk tidak menceritakan hal yang akan membuat sang nenek sedih. Rasa marah akan keadaannya tidak ditunjukkan oleh subjek, maka subjek tidak menunjukkan adanya rasa keterasingan.

Subjek A merasa senang tinggal dengan nenek, menganggap nenek sebagai orang tuanya sendiri dan merasa bahwa neneklah yang paling peduli padanya. Komunikasi subjek dengan nenek pun berjalan baik, mereka saling berbagi cerita dan saling memberikan pendapat dalam memutuskan sesuatu. Terkadang subjek merasa bahwa keputusan neneknya tidak bisa diubah, dan subjek pun menerima. Pola asuh nenek yang ketat justru menunjukkan rasa kurang percaya dari nenek kepada subjek. Subjek menunjukkan aspek keterasingan yang rendah, ketika ia ditanya mengenai sosok yang paling peduli padanya, subjek awalnya mengatakan bahwa tidak ada sosok yang peduli padanya, namun subjek menyebut nenek setelah memikirkannya beberapa saat.

Subjek $\mathrm{N}$ sudah menerima dan terbiasa tinggal dengan nenek. Subjek menganggap nenek sebagai orang tuanya sendiri, walau ia merasa terdapat perbedaan dengan orang tua kandung. Nenek merupakan sosok yang paling peduli dengan subjek. Intensitas subjek untuk berbincang dan curhat dengan nenek sudah berkurang dibanding sebelumnya, karena kondisi nenek yang sudah mulai pikun. Selain itu nenek juga kurang mengerti mengenai hal-hal yang diceritakan. Dari sini dapat disimpulkan bahwa subjek tidak menunjukkan adanya rasa keterasingan.

Keempat subjek menunjukkan kelekatan yang aman dengan nenek, hal ini tampak dari ketiga aspek kelekatan yang telah dilihat. Keempat subjek menunjukkan adanya aspek kepercayaan dan komunikasi dengan nenek. Sedangkan pada aspek keterasingan, terdapat satu subjek yang menunjukkan aspek keterasingan yang rendah sedangkan tiga subjek lainnya tidak menunjukkan adanya aspek keterasingan.

\section{Hubungan dengan Orang Tua}

Keempat subjek yang tinggal dan diasuh oleh nenek sejak kecil tetap menjalin hubungan yang baik dengan orang tua kandung. Keempat subjek masih menjalin komunikasi dan masih bertemu dengan orang tua mereka dengan frekuensi yang berbeda-beda. Tiga dari empat subjek tetap merasa nyaman dengan orang tua, sedangkan satu subjek merasa tidak dekat dengan orang tuanya.

Terkadang subjek tidak bisa leluasa bertemu dengan ibunya karena tidak diberi izin oleh ayah tirinya. Meskipun demikian, subjek tetap merasa nyaman dengan sang ibu. Subjek yang ditinggal ibu untuk bekerja keluar negeri hingga sang ibu meninggal dunia bahkan tetap merasa dekat dengan ibunya walau berkomunikasi hanya sekali dalam seminggu. Fatkhurohmah et al. (2019) menyebutkan bahwa meskipun anak tidak tinggal bersama orang tua, komunikasi yang dijalin sejak dini akan sangat berguna dalam membentuk kelekatan antara anak dengan orang tua.

\section{Pengaruh Pengasuhan Nenek}

Pengasuhan yang diterapkan nenek berbeda-beda pada setiap subjek. Ada nenek yang menerapkan pola asuh ketat, ada nenek yang memanjakan, ada nenek yang menerapkan pola asuh yang tegas, ada nenek yang menerapkan pola asuh yang tidak terlalu ketat dan tidak pula terlalu longgar. Berbagai pola asuh yang diterapkan oleh nenek memberikan pengaruh pada subjek. 
Subjek B mendapat pelajaran dari pola asuh yang diterapkan oleh nenek untuk selalu bekerja keras dan mandiri. Dari pola asuh yang diterapkan nenek menjadikan Subjek B juga menjadi pribadi yang ikhlas, mampu melihat berbagai hal dari sisi positif, dan tetap merasa bahagia. Kelak, subjek B ingin menerapkan pola asuh yang diterima kepada anaknya.

Subjek D merasa neneknya selalu mengajarkan tentang kebaikan. Nenek subjek tidak menerapkan pengasuhan yang terlalu ketat namun tetap tegas. Saat ini subjek berkeinginan untuk membanggakan neneknya. Subjek menginginkan agar anaknya kelak lebih baik dari dirinya.

Subjek A diasuh oleh nenek dengan model pengasuhan yang ketat tetapi nenek kurang mampu dalam mengendalikan emosi. Namun dari pengasuhan nenek yang seperti itu tidak mempengaruhi diri subjek. Subjek justru belajar dari lingkungannya yang banyak konflik. Subjek menjadi pribadi yang sabar dan ikhlas dengan semua yang terjadi, mau mengerti keadaan orang lain, dan tidak mudah terbawa emosi. Subjek mengatakan tidak ingin mengasuh anaknya kelak dengan pengasuhan yang ketat seperti pola asuh dari sang nenek. Subjek ingin anaknya memahami agama, memiliki attitude, sopan santun, dan adab.

Subjek $\mathrm{N}$ diasuh oleh nenek yang selalu menuruti keinginannya, sehingga ia menjadi pribadi yang manja. Namun kehadiran ibu subjek membawa perubahan pada diri subjek menjadi tidak terlalu manja. Nenek subjek yang sabar membuat subjek belajar untuk menjadi orang yang penyabar pula. Subjek mengatakan tidak ingin memanjakan anaknya kelak dan tidak pula terlalu keras pada anaknya.

Subjek yang tinggal dan diasuh oleh neneknya juga merasa sedih, iri dan merasa ingin seperti orang lain yang tinggal dengan orang tua kandung. Hal ini sesuai dengan penelitian Beazley et al. (2018) yang menemukan bahwa anak yang tidak tinggal dengan orang tua menunjukkan respon emosional yang negatif. Subjek yang diasuh nenek juga menunjukkan kemandirian, kesabaran, kerja keras, yang sesuai dengan penelitian Breheny et al. (2013) bahwa pengasuhan tidak selalu nenek berpengaruh negatif pada sang anak. Pengasuhan nenek yang dirasakan subjek yaitu penuh kasih sayang, perhatian, membuat anak merasa bahagia dan nyaman. Hal ini sesuai dengan penelitian Gottzén dan Sandberg (2019) yang menyatakan bahwa pengasuhan nenek yang baik akan berpengaruh baik pula kepada sang anak.

\section{Kelekatan Subjektif}

Selain melihat kelekatan subjek dengan nenek serta hubungan mereka dengan orang tua kandung, peneliti juga menanyakan perihal sosok yang dianggap subjek paling dekat dengannya. Satu subjek dengan yakin mengatakan bahwa ia paling dekat dengan neneknya. Dua subjek justru mengatakan bahwa mereka merasa lebih dekat dengan ibu meskipun terpisah jarak hingga puluhan tahun. Satu subjek mengatakan bahwa ia merasa dekat dengan sang nenek, namun belakangan menjadi lebih dekat dengan ibu karena usia nenek yang semakin tua dan kurang memahami hal yang disampaikan oleh subjek. Hal ini membuktikan bahwa penelitian yang dilakukan oleh Cenceng (2015) yaitu figur lekat utama anak adalah ibu. Subjek yang tidak dibesarkan oleh ibu akan tetap menganggap ibu sebagai figur yang paling dekat dan selalu memahami serta selalu ada untuknya.

\section{Kesimpulan dan Saran}

Berdasarkan analisis data yang telah dilakukan ditarik kesimpulan bahwa anak yang diasuh oleh nenek sejak kecil memiliki kelekatan yang aman dengan sang nenek. Hal ini ditunjukkan oleh 
tingginya aspek komunikasi dan kepercayaan, serta rendahnya aspek keterasingan. Kelekatan yang aman antara anak dengan nenek tidak menutup terbentuknya kelekatan antara anak dengan orang tua kandungnya. Subjek tetap menjalin komunikasi dan sesekali bertemu dengan orang tua mereka. Beberapa subjek bahkan merasa lebih dekat dengan ibu mereka walaupun telah lama berpisah.

Mengasuh dan membesarkan cucu bagi nenek tentu tidak mudah, maka peneliti memberikan saran kepada orang-orang sekitar khususnya keluarga agar senantiasa memberikan dukungan kepada nenek maupun kakek yang mengasuh cucu mereka. Hal ini sejalan dengan penelitian Wang et al. (2019) yang menyatakan bahwa kakek nenek yang mengasuh cucu mereka memperoleh dukungan yang minim. Mengasuh cucu bahkan meningkatkan gejala depresi pada nenek dan kakek (Minkler et al., 1997), maka sangat disarankan untuk memberi dukungan kepada nenek dan kakek yang mengasuh cucu mereka.

Saran bagi peneliti selanjutnya agar melakukan wawancara dengan orang-orang terdekat subjek dan dengan nenek subjek agar dapat diperoleh data yang lebih meluas.

\section{Daftar Pustaka}

Ainsworth, M. D. S., \& Bowlby, J. (1991). An Ethological Approach to Personality Development. In American Psychologist (Vol. 46, Issue 4).

Armsden, G. C., \& Greenberg, M. T. (1987). The inventory of parent and peer attachment: Individual differences and their relationship to psychological well-being in adolescence. Journal of Youth and Adolescence, 16(5), 427-454. https://doi.org/10.1007/BF02202939

Beazley, H., Butt, L., \& Ball, J. (2018). 'Like it, don't like it, you have to like it': children's emotional responses to the absence of transnational migrant parents in Lombok, Indonesia. Children's Geographies, 16(6), 591-603. https://doi.org/10.1080/14733285.2017.1407405

Braun, V., \& Clarke, V. (2006). Using thematic analysis in psychology. Qualitative Research in Psychology, 3(2), 77-101. http://dx.doi.org/10.1191/1478088706qp063oa

Breheny, M., Stephens, C., \& Spilsbury, L. (2013). Involvement without interference: How grandparents negotiate intergenerational expectations in relationships with grandchildren. Journal of Family Studies, 19(2), 174-184. https://doi.org/10.5172/jfs.2013.19.2.174

Cenceng. (2015). Perilaku Kelekatan Pada Anak Usia Dini (Perspektif John Bowlby). Lentera, IXX(2), 141-153.

Creswell, J. W., \& Poth, C. N. (2018). Qualitative Inquiry \& Research Design. In Sage (fourth edi).

Desrosiers, H., Cardin, J.-F., \& Belleau, L. (2013). The Impact of Parental Separation on Young Children's Mental Health. Institut de La Statistique, 6(3), 1-16.

Edwards, O. W. (2018). School perceptions of children raised by grandparents. Journal of Applied School Psychology, 34(1), 86-100. https://doi.org/10.1080/15377903.2017.1403401

Fatkhurohmah, D., Karim, M. B., \& Nisa, T. F. (2019). Kelekatan Anak Keluarga Tenaga Kerja Wanita. 5(2), 199-216. 
Triska Novira dan Zulian Fikry

Gottzén, L., \& Sandberg, L. (2019). Creating safe atmospheres? Children's experiences of grandparents' affective and spatial responses to domestic violence. Children's Geographies, 17(5), 514-526. https://doi.org/10.1080/14733285.2017.1406896

Janesick, V. J. (2007). Peer debriefing. In The Blackwell Encyclopedia of Sociology (pp. 1-2). https://doi.org/10.1002/9781405165518.wbeosp014.pub2

Maguire, M., \& Delahunt, B. (2017). Doing a thematic analysis: a practical, step by step guide for learning and teaching scholars. IEEE Transactions on Industry Applications, 8(3). https://doi.org/10.1109/TIA.2014.2306979

Minkler, M., Fuller-Thomson, E., Miller, D., \& Driver, D. (1997). Depression in grandparents raising grandchildren: results of a national longitudinal study. Archieves of Family Medicine, 6(5), 445452.

Papalia, D. E., Olds, S. W., \& Feldman, R. D. (2009). Human Development (eleventh e). McGraw-Hill Companies. https://b-ok.asia/book/5474918/379a8d

Statham, J. (2011). Grandparents providing child care. London: Childhood Wellbeing Research Centre. Sugiyono. (2013). Metode penelitian kuantitatif, kualitatif, dan R\&D. Alfabeta.

Wang, C. D., Jr, B. H., Sun, Q., \& Zhu, W. (2019). Grandparents as the primary care providers for their grandchildren: a cross-cultural comparison of Chinese and US samples. The International Journal of Aging and Human Development, 84(4), 331-355. 